\title{
Light-responsive hybrids based on carbon nanotubes with covalently attached PHEMA- $g$-PCL brushes
}

Katarína Mosnáčková ${ }^{*}$, Miroslav Mrlík ${ }^{2}$, Matej Mičušík ${ }^{1}$, Angela Kleinová ${ }^{1}$, Vlasta Sasinková $^{3}$, Anton Popelka ${ }^{4}$, Alena Opálková Šišková ${ }^{1}$, Peter Kasák $^{4, *}$, Claudia L. Dworak ${ }^{5}$, Jaroslav Mosnáček ${ }^{1,6 *}$

${ }^{1}$ Polymer Institute, Slovak Academy of Sciences, Dúbravská cesta 9, 84541 Bratislava, Slovakia

${ }^{2}$ Centre of Polymer Systems, University Institute, Tomas Bata University in Zlin, trida Tomase Bati 5678, 76001 Zlin, Czech Republic

${ }^{3}$ Institute of Chemistry, Slovak Academy of Sciences, Dúbravská cesta 9 84538 Bratislava, Slovakia

${ }^{4}$ Center for Advanced Materials, Qatar University, Doha 2713, Qatar

${ }^{5}$ Institute of Applied Synthetic Chemistry, Vienna University of Technology, Getreidemarkt 9, A1060 Vienna, Austria

${ }^{6}$ Centre for Advanced Materials Application, Slovak Academy of Sciences, Dubravska cesta 9, 84511 Bratislava, Slovakia

Corresponding authors: Katarína Mosnáčková: katarina.mosnackova@savba.sk; Peter Kasák: peter.kasak@qu.edu.qa; Jaroslav Mosnáček: jaroslav.mosnacek@savba.sk 


\section{SUPPLEMENTARY INFORMATION}

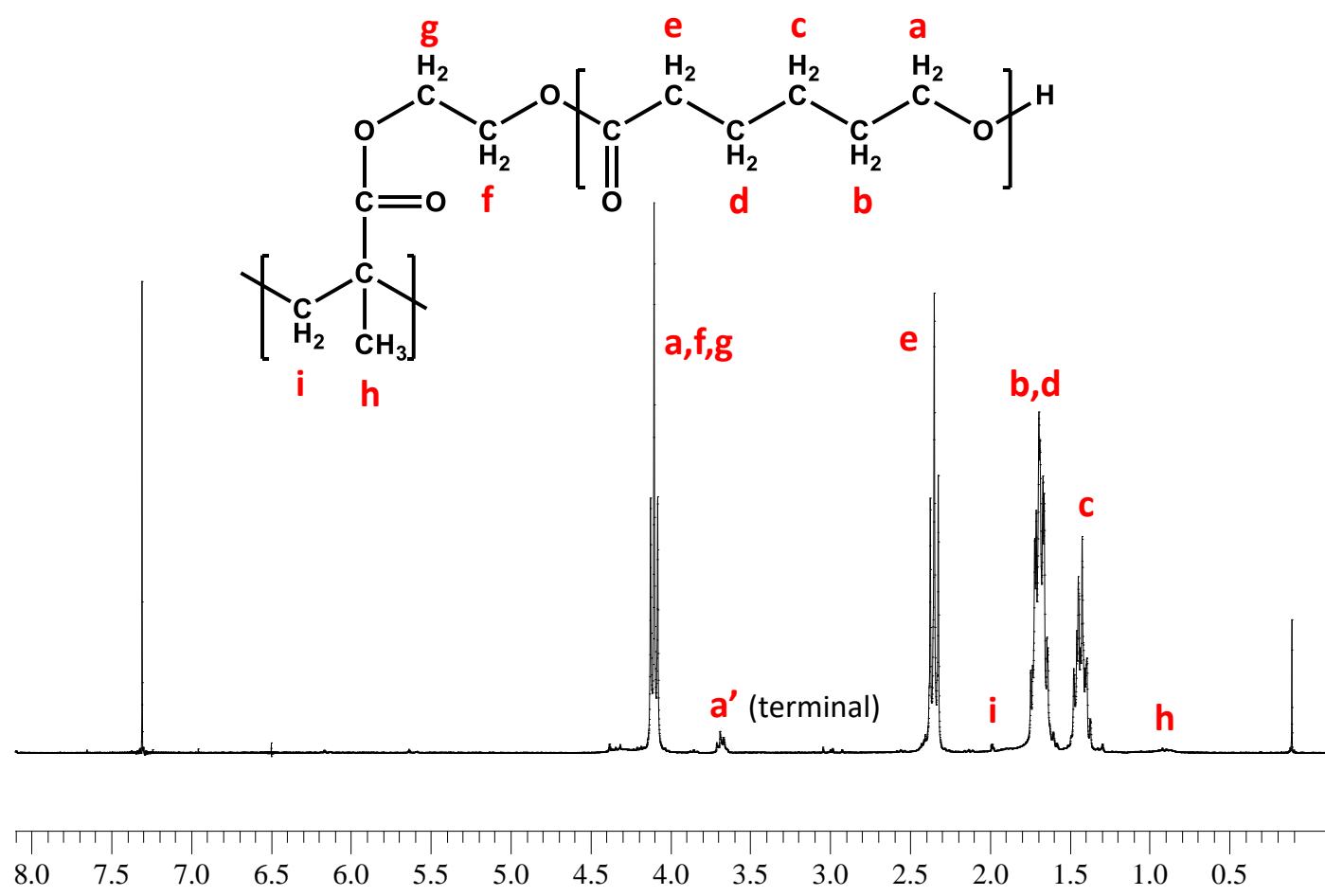

Figure S1. ${ }^{1} \mathrm{H}$ NMR of PHEMA-g-PCL copolymer measured in $\mathrm{CDCl}_{3}$.

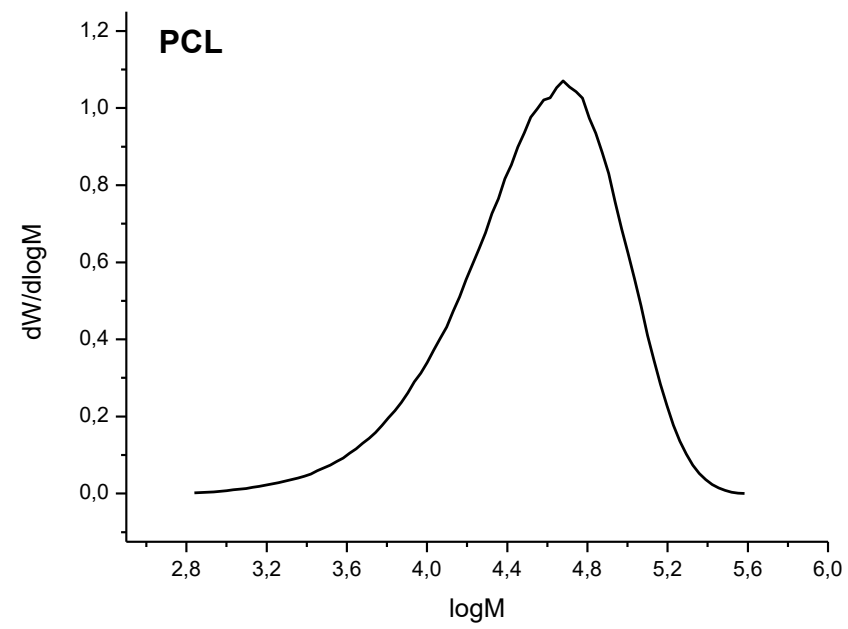

Figure S2. GPC traces of non-grafted PCL in chloroform formed during synthesis of MWCNTsPHEMA- $g$-PCL hybrids; $M_{\mathrm{n}}=22,600 \mathrm{~g} \mathrm{~mol}^{-1}, Ð=2.3$, PS standards. 


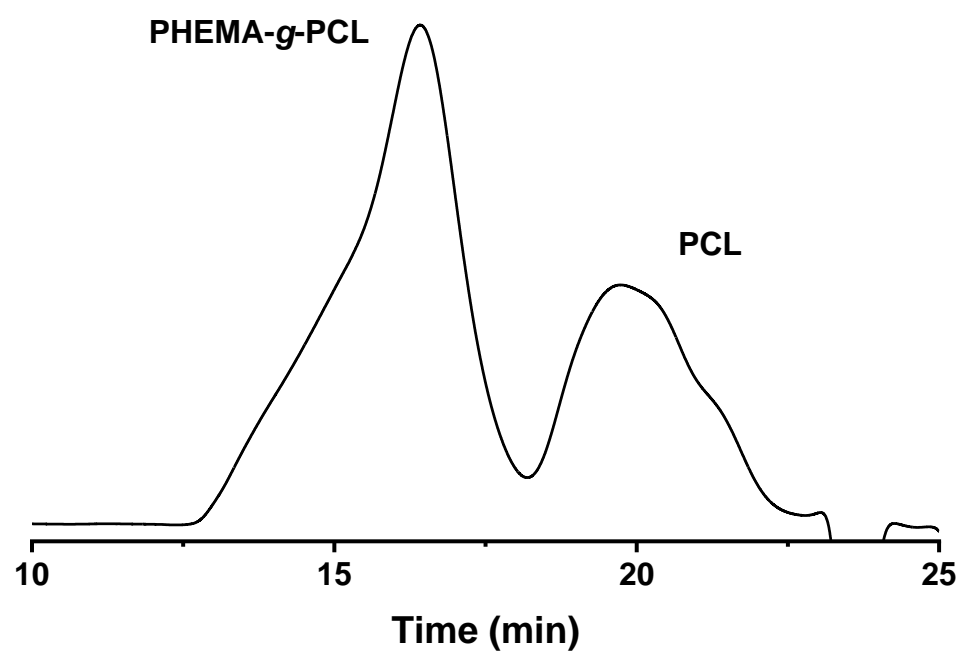

Figure S3. GPC elugram in chloroform showing content of PCL homopolymer $\left(M_{\mathrm{n}}=3400 \mathrm{~g} \mathrm{~mol}^{-}\right.$ $\left.{ }^{1} D=1.74\right)$ formed during synthesis of PHEMA- $g$-PCL copolymer $\left(M_{\mathrm{n}}=139,000 \mathrm{~g} \mathrm{~mol}^{-1}, \oslash=\right.$ 1.93); PS standards.

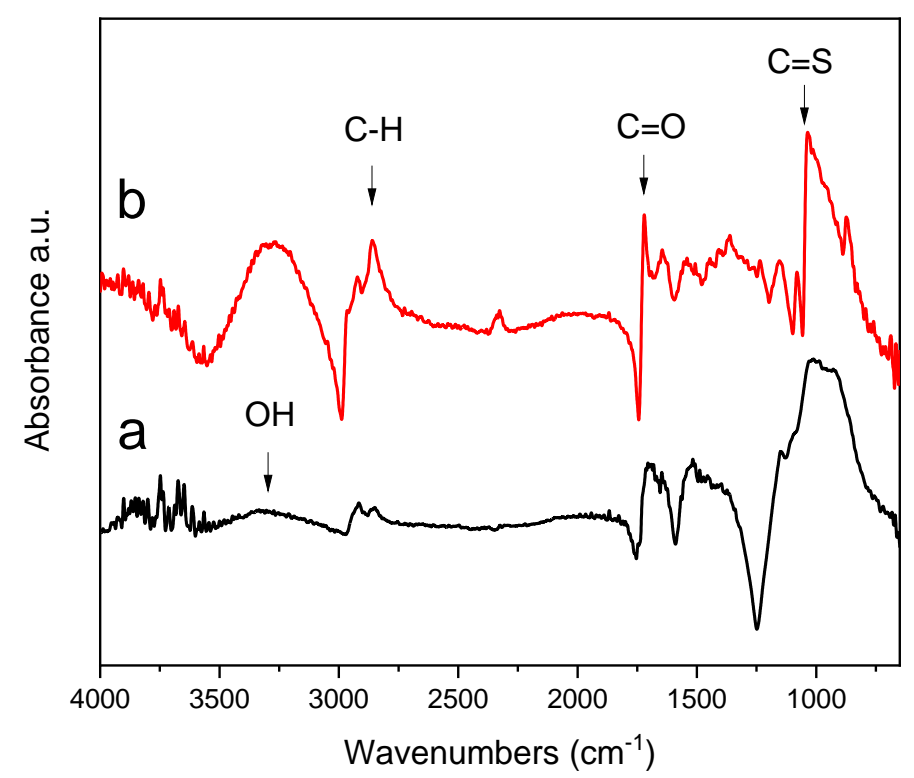

Figure S4. FTIR spectra of a) MWCNTs-OH and b) MWCNTs-CPAD. 


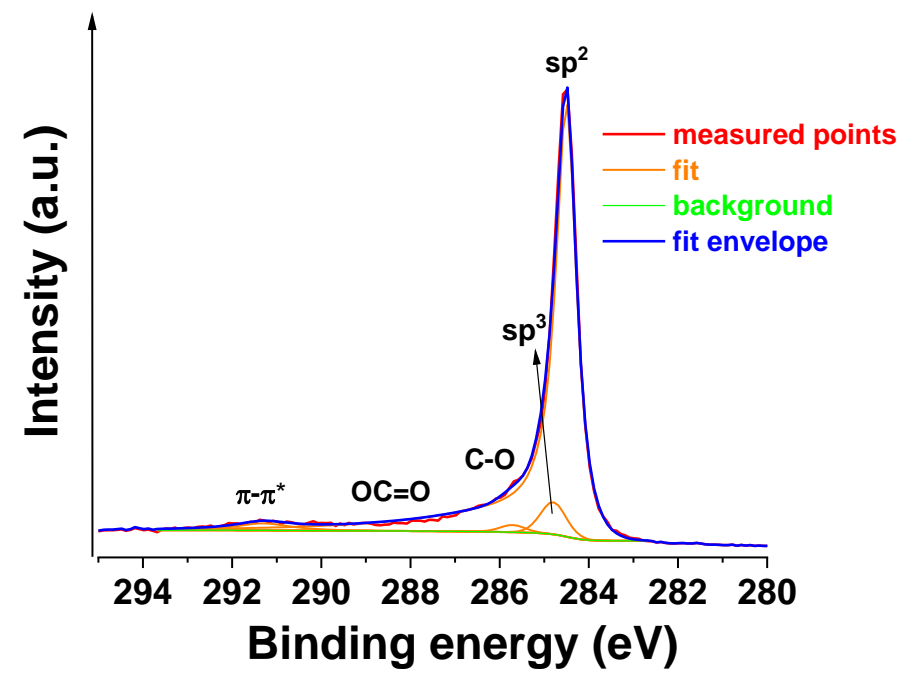

Figure S5. XPS data of C1s region of neat MWCNTs

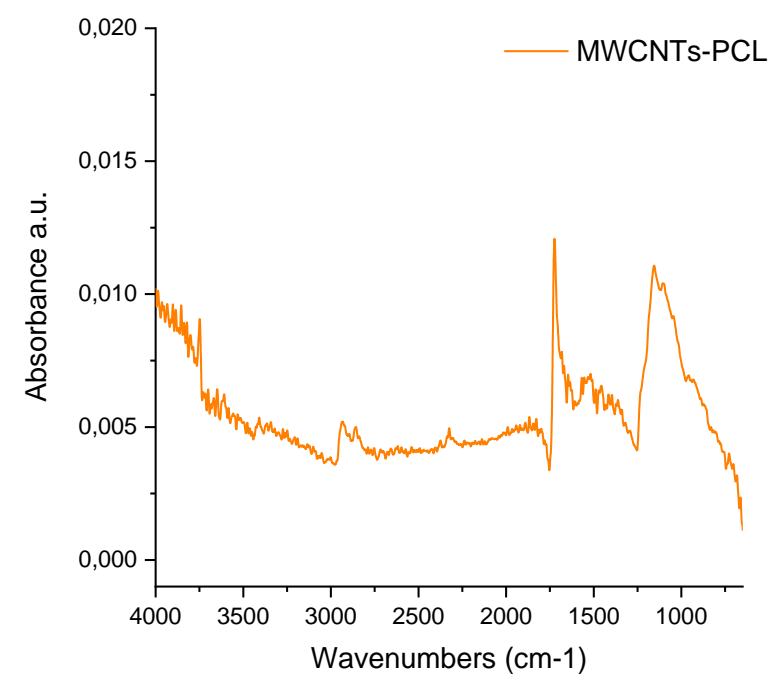

Figure S6. FTIR spectrum of MWCNTs-PCL. 
The successful grafting of PCL chains directly onto the MWCNTs surface was confirmed by XPS analysis showed on Figure S7 where is clearly visible the increase of oxygen signal after acid treatment and after following direct ROP polymerization of $\varepsilon-\mathrm{Cl}$ (Table 1). The presence of PCL after direct ROP polymerization of $\varepsilon-\mathrm{Cl}$ on the surface of MWCNTs is confirmed by typical C1s signals of PCL centered at $\sim 285.0 \mathrm{eV}\left(\mathrm{C}-\mathrm{C}, \mathrm{sp}^{3}\right)$, at $\sim 286.3 \mathrm{eV}(\mathrm{C}-\mathrm{O})$ and at $\sim 289.0 \mathrm{eV}(\mathrm{OC}=\mathrm{O})$, see Figure $S 7 b{ }^{1}$. The peaks belonging to $\operatorname{Sn} 3 p\left(\operatorname{Sn} 3 p^{3 / 2}\right.$ at $\sim 718 \mathrm{eV}$ and $\operatorname{Sn} 3 \mathrm{p}^{1 / 2}$ at $\left.\sim 759 \mathrm{eV}\right)$ and $\mathrm{Sn} 3 \mathrm{~d}\left(\mathrm{Sn} 3 \mathrm{~d}^{5 / 2}\right.$ at $\sim 488 \mathrm{eV}$ and $\mathrm{Sn} 3 \mathrm{~d}^{3 / 2}$ at $\left.\sim 496 \mathrm{eV}\right)$ originated from catalyst residue were also recorded ${ }^{2}$. The relatively strong signal of $\mathrm{sp}^{2}$ carbon (Figure S7b, Table S1) indicates very thin PCL layer due to low grafting density, similarly as discussed for MWCNTs-PHEMA.

a)

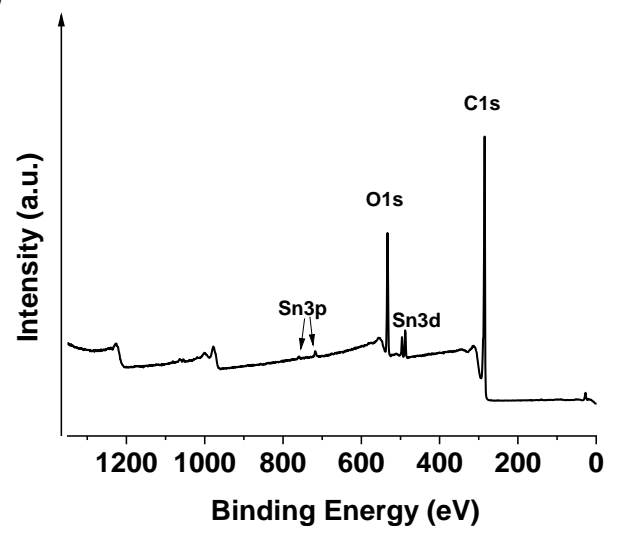

b)

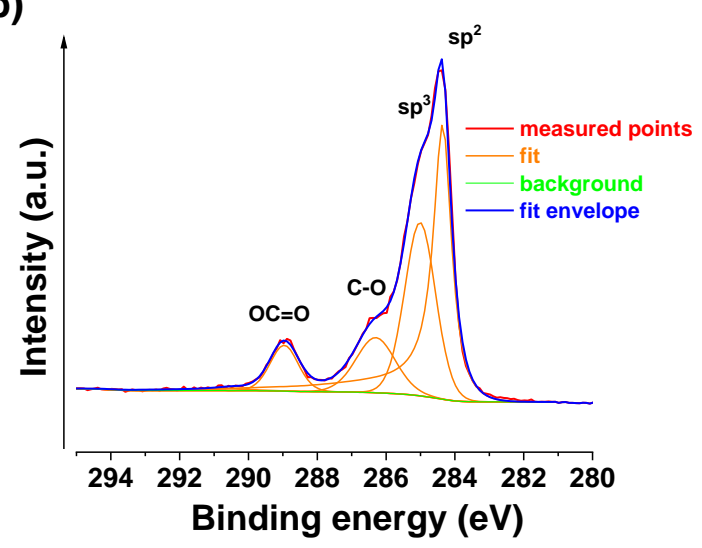

Figure S7. XPS data of MWCNTs-PCL a) whole spectra, b) C1s region. 
Table S1. Surface composition of MWCNTs-PCL in atomic percentage as determined from the XPS survey spectra.

\section{Surface chemical composition (at.\%)}

\begin{tabular}{l|cccc}
\hline Labeling & O1s & $\mathrm{C} 1 \mathrm{~s}$ & $\mathrm{~S} 2 \mathrm{p}$ & $\mathrm{Cl} 2 \mathrm{p} /$ \\
& $\mathrm{C}=\mathrm{O}_{\mathrm{ar}} / \mathrm{C}=\mathrm{O}_{\mathrm{a}} / \mathrm{C}-\mathrm{O} / \#$ & $\mathrm{sp}^{2} / \mathrm{sp}^{3} / \mathrm{CO} / \mathrm{C}=\mathrm{O} / \mathrm{OCO} / *$ & $\mathrm{~N} 1 \mathrm{~s} / \mathrm{Si} 2 \mathrm{p} / \mathrm{Sn} 3 \mathrm{~d}$ \\
\hline MWCNTs-PCL & 17.1 & 82.5 & $-/-/-/ 0.4$ \\
& $2.3 / 6.7 / 7.3 / 0.8$ & $38.0 / 26.8 / 10.8 /-/ 6.5 / 0.4$ & \\
\hline & \# referring to $\mathrm{O} 2 \mathrm{C}=\mathrm{O}$ signal, ${ }^{1} *$ referring to $\pi-\pi^{*}$ signal
\end{tabular}

The intensity of the D-band was examined by comparing the $\mathrm{D} / \mathrm{G}$ ratios within a given spectra. This approach prevents the problems with variations in the surface roughness, the collection efficiency of the optics, and other extrinsic effects which can cause the absolute Raman signals to vary in intensity by as much as $50 \%$ even for identical samples ${ }^{3}$.
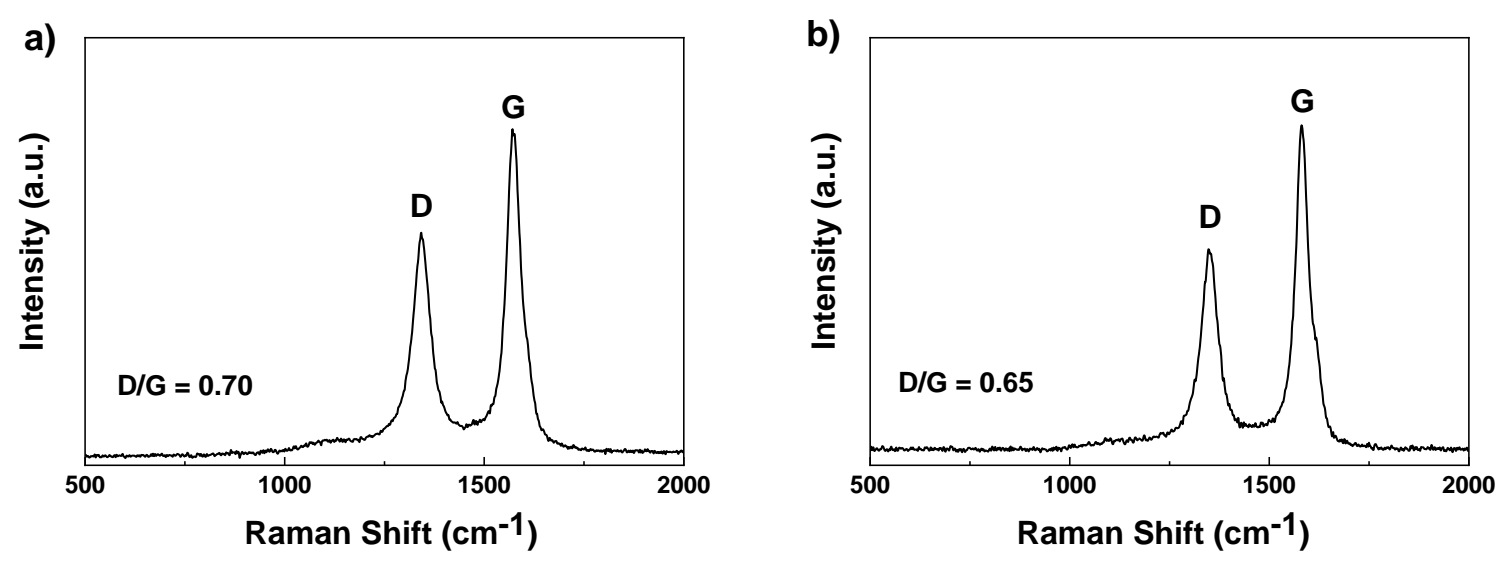

Figure S8. Raman spectra of (a) MWCNTs-OH and (b) (d) MWCNTs after cleavage of PHEMA 


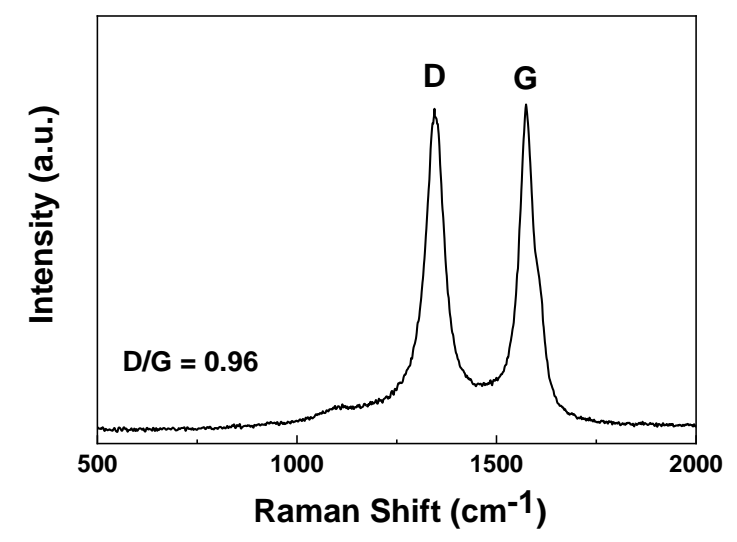

Figure S9. Raman spectra of MWCNTs-PCL

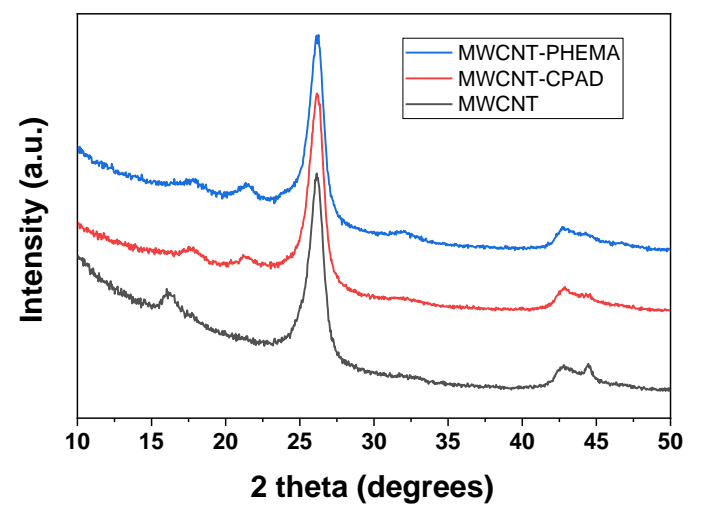

Figure S10. The XRD pattern of neat MWCNTs, MWCNTs modified with RAFT agent and MWCNTs grafted with PHEMA 

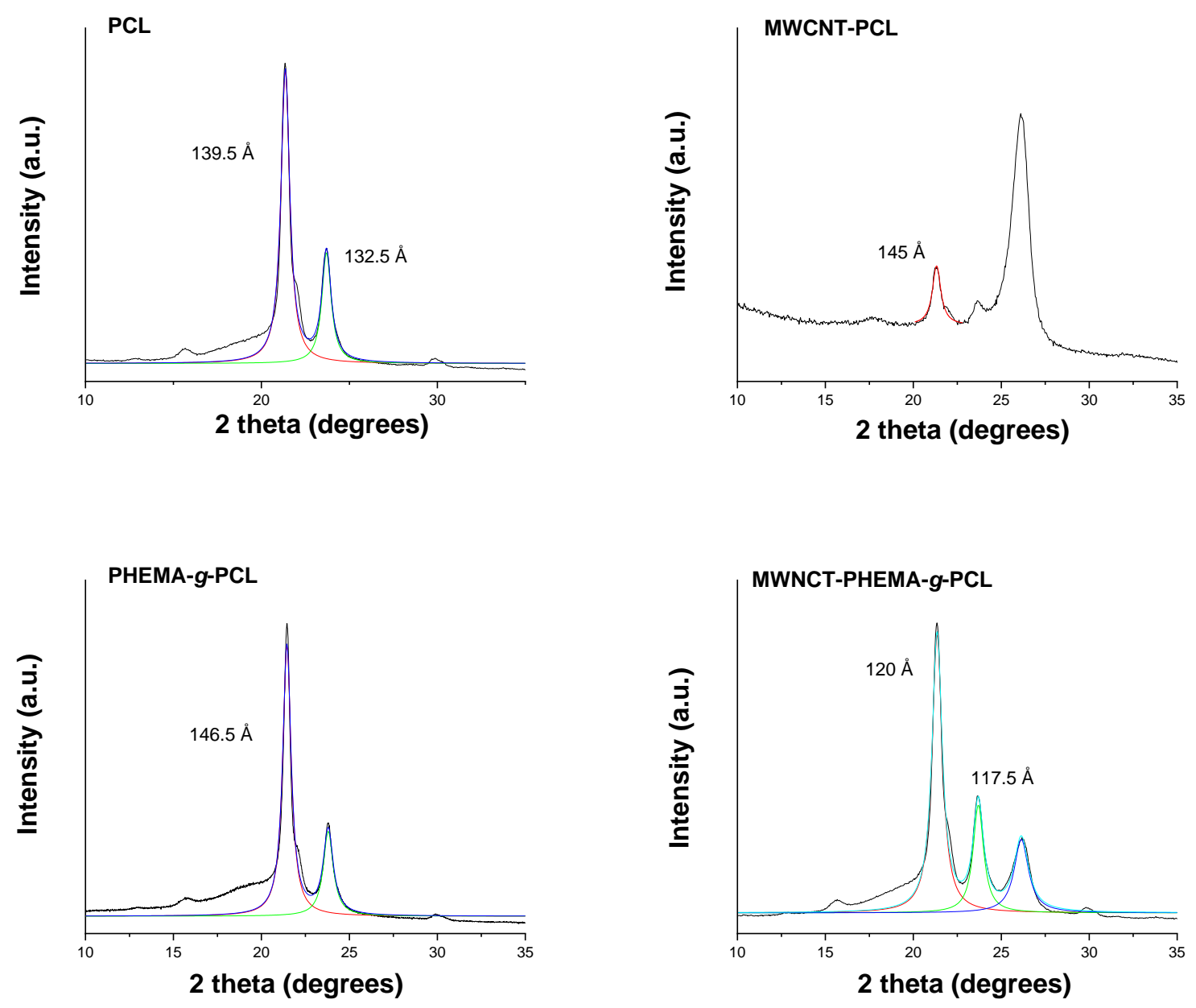

Figure S11. Fits of the XRD pattern and values of PCL crystallites size calculated from FWHM values for pure PCL, MWCNTs-PCL, PHEMA- $g$-PCL, and MWCNTs-PHEMA- $g$-PCL. 

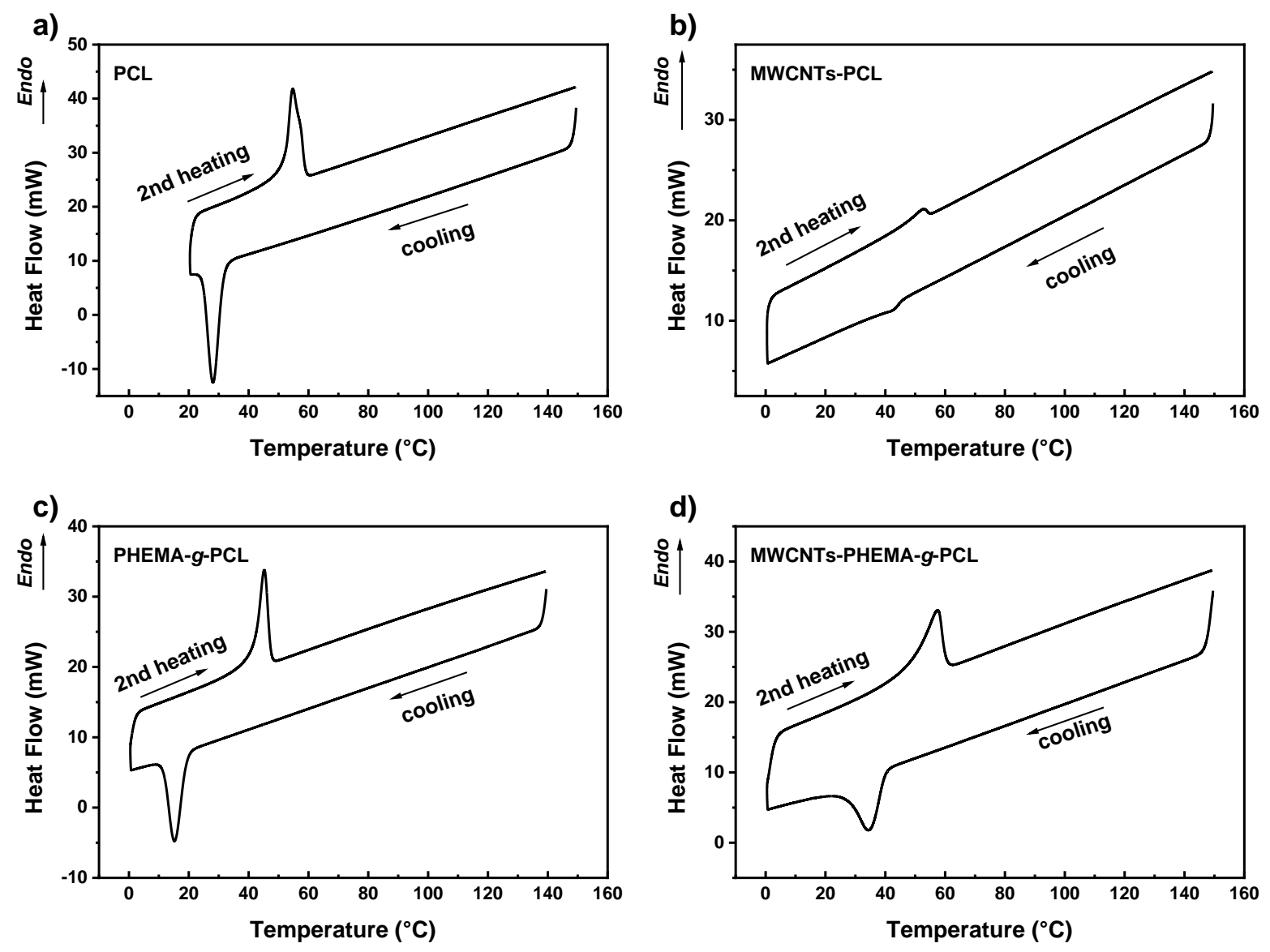

Figure S12. DSC curves of cooling and 2nd heating for a) pure PCL, b) MWCNTs-PCL, c) PHEMA-gPCL and d) MWCNTs-PHEMA-g-PCL

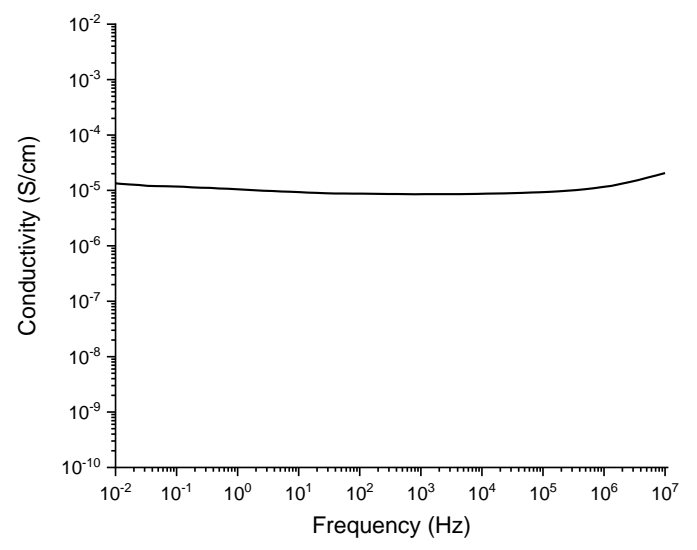

Figure S13. Change of electric conductivity of MWCNTs-PHEMA-g-PCL with change of frequency. 

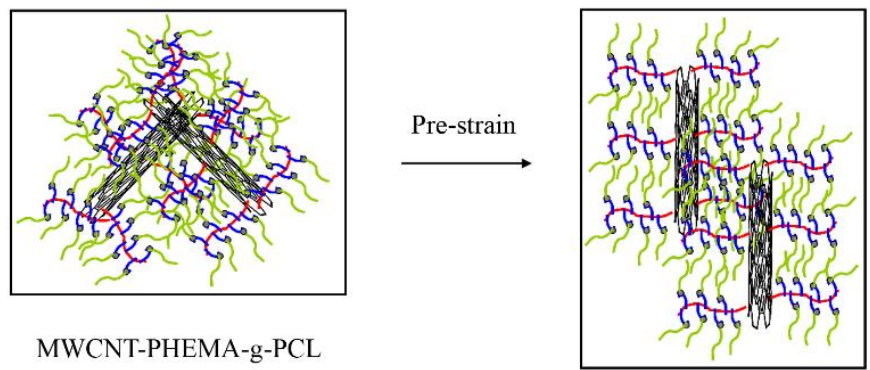

Light on
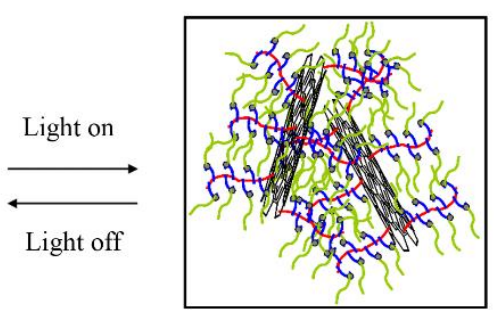

MWCNT-PHEMA-g-PCL

Figure S14. Schematic illustration of photo-mechanical actuation of MWCNTs-PHEMA- $g$-PCL.

\section{Calculation of grafting density of the PHEMA and PCL chains in MWCNTs-PHEMA or}

\section{MWCNTs-PCL hybrids:}

grafting density $=\frac{w_{P} \times N_{A} \times 10^{-18}}{w_{C N T} \times M_{n} \times S}$ chains $/ \mathrm{nm}^{2}$

where:

$\mathrm{w}_{\mathrm{p}}$ and $\mathrm{w}_{\mathrm{CNT}}$ are weight fractions of the grafted polymer chains (PHEMA or PCL) and neat MWCNT (residual weight fraction at $450^{\circ} \mathrm{C}$ ), respectively, determined from TGA of MWCNTPHEMA or MWCNT-PCL;

$M_{\mathrm{n}}$ is number average molar mass of the grafted polymer (PHEMA or PCL) in $\mathrm{g} / \mathrm{mol}$;

$\mathrm{S}$ is specific surface area of MWCNTs - here we used $320 \mathrm{~nm}^{2} / \mathrm{g}$;

$\mathrm{N}_{\mathrm{A}}$ is Avogadro constant. 


\section{Calculation of weight fractions of the individual blocks of PHEMA-g-PCL copolymer in} MWCNTs-PHEMA-g-PCL based on TGA analysis:

$$
\begin{aligned}
& B_{1}{ }^{\prime}=\frac{B_{1} \times(100-C)}{100-A} \\
& {B_{2}}^{\prime}=\frac{C-A}{100-A} \times 100
\end{aligned}
$$

where:

$\mathrm{A}$ is decrease in TGA of MWCNTs-PHEMA in the temperature range upto $450^{\circ} \mathrm{C}$ - here it was $10.5 \mathrm{wt} \%$

$\mathrm{C}$ is decrease in TGA of MWCNTs-PHEMA-g-PCL in the temperature range upto $450^{\circ} \mathrm{C}$ - here it was $76 \mathrm{wt} \%$;

$\mathrm{B}_{1}$ is weight fraction (in percentage) of the PHEMA in TGA of MWCNTs-PHEMA (calculated by similar way from changes between MWCNTs-CPAD and MWCNTs-PHEMA) - here it was $6.8 \mathrm{wt} \%$

$\mathrm{B}_{1}{ }^{\prime}$ is weight fraction (in percentage) of the PHEMA in TGA of MWCNTs-PHEMA-g-PCL here it was calculated to be $1.8 \mathrm{wt} . \%$;

$\mathrm{B}_{2}$ ' is weight fraction (in percentage) of the PCL in TGA of MWCNTs-PHEMA-g-PCL - here it was calculated to be 73.2 wt.\%;

Thus after recalculation of PCL:PHEMA of 40.7:1 (w/w) to molar ratio based on molecular weights of the CL and HEMA monomers, molar ratio of CL:HEMA was approximately 46:1. 


\section{References}

(1) Hantsche, H. High Resolution XPS of Organic Polymers, the Scienta ESCA300 Database. By G.

Beamson and D. Briggs, Wiley, Chichester 1992, 295 Pp., Hardcover, f 65.00, ISBN 0-471-93592-1. Adv. Mater. 1993, 5 (10), 778-778. https://doi.org/10.1002/adma.19930051035.

(2) Sedlařík, V.; Vesel, A.; Kucharczyk, P.; Urbánek, P. A Novel Approach for Qualitative Determination of Residual Tin Based Catalyst in Poly(Lactic Acid) by X-Ray Photoelectron Spetroscopy. Mater.

Technol. 2011, 45 (3), 213-216.

(3) Dillon, A. C.; Parilla, P. A.; Alleman, J. L.; Gennett, T.; Jones, K. M.; Heben, M. J. Systematic Inclusion of Defects in Pure Carbon Single-Wall Nanotubes and Their Effect on the Raman D-Band. Chem. Phys. Lett. 2005. https://doi.org/10.1016/j.cplett.2004.11.104. 